\title{
UNIVERSIDADE CORPORATIVA: UMA NOVA “ROUPAGEM” PARA A ÁREA DE TREINAMENTO DE DESENVOLVIMENTO?
}

\author{
CORPORATE UNIVERSITY: A NEW “GUISE” FOR THE AREA OF TRAINING AND DEVELOPMENT
}

DOI: http://dx.doi.org/10.12712/rpca.v5i1.20

\section{Alvacir Cili Comper Conte \\ SENAC - SC}

\section{Flávio Ramos}

Universidade do Vale do Itajaí

Sérgio Saturnino Januario

Universidade do Vale do Itajaí

\section{RESUMO}

A literatura atual contempla mudanças significativas nas formas como organizações alteraram as práticas de treinamento e desenvolvimento chegando a um suposto novo patamar, no que configuraria um original desenho com características inéditas de aprendizagem, transformando e superando paradigmas mecanicistas nas práticas de gestão. 0 tema universidade corporativa adquiriu relevância nestes últimos anos no país, pois estaria viabilizando uma migração do centro de T\&D tradicional para a chamada universidade corporativa. 0 artigo busca conceituar universidade corporativa, para que equívocos não sejam cometidos pela literatura da administração, bem como apresenta reflexões relacionadas se há, de fato, uma transformação efetiva nas práticas tradicionais da área de recursos humanos e da própria concepção de gestão ou se esses modelos seriam mais um modismo no campo da administração.

Palavras-chave: Universidade corporativa. Recursos humanos. Treinamento edesenvolvimento.

\begin{abstract}
The current literature contemplates significant changes in the ways in which organizations have altered their training and development practices, arriving at a supposed new level, consisting of an original design, but with new learning characteristics, transforming and overcoming mechanistic paradigms in management practices. The theme of the corporate university has gained importance in Brazil in recent years, as it enables a migration from the traditional center of T\&D to the so-called corporate university. This article seeks to define the corporate university, in order to avoid mistakes by the literature of business administration, and to present some reflections on whether there has been, in fact, effective transformation in the traditional practices of the area of human resources and the very concept of management, or whether these models are just another fad in the field of business administration.
\end{abstract}

Keywords: Corporate university. Human resources. Training and development. 



\section{INTRODUÇÃo}

A ênfase da educação nas organizações contemporâneas tem como foco o desenvolvimento da capacidade do indivíduo aprender (MASCARENHAS, VASCONCELOS e VASCONCELOS, 2004; VASCONCELOS e MASCARENHAS, 2007). Mas os modelos de gestão parecem refletir as ambigüidades e os paradoxos organizacionais (REED, 1998; CLEGG e HARDY, 1998; NOGUEIRA, 2004; VASCONCELOS e VASCONCELOS, 2004; BERTERO, 2006; ASTLEY e VAN de VEM, 2007). Barbosa (2002) e Sainsaulieu e Kirschner (2006) ressaltam ainda a importância das variáveis culturais e sociais que interagem sobre o campo organizacional, considerado por esses autores um sistema que se apresenta de forma especial nos processos que envolvem as políticas de recursos humanos.

Os discursos se multiplicam nos congressos e eventos que abordam a 'função RH' com apelos diversos. Ora a área de recursos humanos precisa ser estratégica, ora RH precisa desenvolver novas metodologias de trabalho. Em outros momentos, o foco ressaltado gira em torno do indivíduo no ambiente organizacional e, portanto, é preciso gerir o conhecimento (apesar da imprecisão deste conceito). O discurso varia: o capital intelectual precisa ser preservado; a gestão agora é por competências; a remuneração precisa ser estratégica etc. Para Gaulejac (2007), diante do discurso gerencialista, até mesmo a ética e os valores humanistas são preteridos diante do pragmatismo e da eficácia.

Apesar dos novos modelos de gestão que surgiram recentemente, estes ainda não proporcionaram as respostas esperadas pelas organizações neste início de milênio. Isto principalmente em função dos desafios organizacionais frente às incertezas crescentes de uma sociedade na qual a imprevisibilidade está presente em todas as iniciativas e propostas de mudanças num ambiente de riscos e incertezas que permeiam a sociedade moderna (BAUMAN, 2001).

Lacombe e Tonelli (2004) registram um paradoxo. Afinal, como conciliar o que é exigido pelas organizações, ou seja, um maior desempenho das pessoas, com o menor comprometimento das empresas?

O setor de recursos humanos das organizações, especificamente a área de treinamento e desenvolvimento, responsável pelo desenvolvimento das pessoas, sofreu mudanças significativas nestes últimos anos (WOOD Jr., 2004; LACOMBE e TONELLI, 2004; DAVEL e VERGARA, 2010). Alguns autores sinalizam que essas mudanças apresentaram um novo conceito de aprendizagem: a Educação Corporativa ou Universidade Corporativa (MEISTER, 1999 e 2005; TEIXEIRA, 2001; EBOLI, 2004; MARCONDES, 2008). Mas até que ponto esse novo desenho organizacional estaria a romper com o paradigma mecanicista e considerar aspectos humanistas ligados ao desenvolvimento do indivíduo e de grupos humanos nas organizações? Afinal, a preocupação com novos modismo na administração é constante e novas propostas de gestão precisam ser analisadas comcautela.

Não é por acaso que a literatura no campo da Administração e os livros de gestão apresentam conteúdos de qualidade e consistência duvidosas (PAES DE PAULA e WOOD JR., 2004; BOLTANSKI e CHIAPELLO, 2009).

O artigo, portanto, busca conceituar universidade corporativa, para que equívocos não sejam cometidos na utilização da expressão, bem como apresenta reflexões relacionadas se há, de fato, uma transformação efetiva nas práticas tradicionais da área de recursos humanos e da própria concepção de gestão a partir das iniciativas envolvendo as universidades corporativas ou se esses modelos seriam mais um modismo no campo daadministração.

\section{MUDANÇAS ORANIZACIONAIS}

As transformações pelas quais passa o processo de produção de conhecimento científico nos últimos anos têm deflagrado oportunidades criativas e de mudanças paradigmáticas sobre conhecimento, ciência, pesquisa, intervenção sobre grupos sociais, proposições teóricas, sobretudo a partir da emergência da questão ambiental. A partir da década de sessenta do século passado os desconfortos 
ou problemas gerados pelos estilos de vida e sistemas de apropriação e de gestão de recursos ambientais e sociais, associado ao paradigma das ciências reducionistas possibilitaram um enorme esforço de superação da fragmentação dessas dimensões (GARCÍA, 1984; SANTOS, 1989 e 2000; HOGAN e VIEIRA, 1992; VIEIRA, 1998 e 2000; MORIN, 1999, 2001, 2002, 2002a e 2005; CASANOVA, 2006).

São as 'novidades' no campo das teorias da administração que colocam os gestores frente a desafios além dos limites dos mesmos em atender as expectativas criadas nas organizações acerca de suas respectivas capacidades em gerir pessoas. 0 ambiente organizacional é plural e caracteriza-se pela complexa interação dos indivíduos que compartilham algumas interpretações e divergem em outras. Essas percepções, distintas, influenciam, na maioria das vezes, o comportamento dos indivíduos na organização, pois os subgrupos organizacionais constituem atores dotados de intenções próprias, não necessariamente em sintonia com o conjunto das diretrizes organizacionais. Os valores organizacionais, por exemplo, estão longe de serem universais e não representam homogeneidade (BARBOSA, 2002; SAINSAULIEU e KIRSCHNER, 2006).

Importante também é não esquecer as ambigüidades inerentes a um novo discurso envolvendo os modelos de gestão de pessoas, com um 'colorido' humanista e a busca efetiva por resultados, inerente a qualquer organização. Os paradoxos, bem ressaltados por Mascarenhas, Vasconcelos e Vasconcelos (2004), Tonelli e Lacombe (2004) e o "sofrimento" organizacional em tempos de rápidas mudanças, como registra Nogueira (2004) podem ser explicados pela própria lógica da dinâmica do capital e da busca incessante por resultados. Desta forma, exigir da área de recursos humanos procedimentos que se ajustem a esse paradoxo torna-se algo cruel. Impossível adotar uma prática que seja a síntese de duas propostas inconciliáveis.

Compreender as organizações como uma construção social produtora e resultado de estruturas e de práticas sociais torna-se essencial para conduzirmos o debate acerca sobre mudança organizacional. É precisamente nessa "zona de escape" que pode-se pensar na universidade corporativa, bem como na aprendizagem organizacional, como alternativa, não para superar as contradições inerentes ressaltadas anteriormente, mas para minimizar os aspectos negativos de uma lógica perversa que não contempla a riqueza das interações sociais no ambiente organizacional.

De qualquer forma, modelos plurais de interpretação do fenômeno organizacional, diferentes perspectivas teóricas e a aceitação de que um mesmo fenômeno, no ambiente organizacional, pode apresentar descrições distintas, constituem, possivelmente, o método mais adequado para que análises organizacionais ganhem consistência (ASTLEY e VAN de VEM, 2007; DAFT e WEICK, 2007).

Empresários, administradores, executivos e gestores em geral preocupam-se excessivamente com os aspectos instrumentais e as formas mecanicistas de gerir que, muitas vezes, esquecem de perceber e analisar a organização como uma construção social. Conhecer a cultura de uma organização é saber interpretar o que está acontecendo atualmente na empresa, as representações, as percepções, as motivações ou desmotivações, as angústias, as frustrações dos trabalhadores no cotidiano organizacional. 0 modelo de universidade corporativa contemplaria tais aspectos?

0 tema - Universidade Corporativa, segundo Garrido (2006, p.84), "é um fenômeno social que tem por base a aprendizagem; trata-se de um processo inerente à complexidade do ser humano integral e de suas relações com o próximo e com o meio ambiente". Mas não seria essa uma perspectiva excessivamente otimista ou, quem sabe, pretensiosa? Representaria, de fato, novas relações sociais envolvendo capital e trabalho nos ambientes empresariais?

\section{UNIVERSIDADE CORPORATIVA}

Ao longo do século XX, as teorias organizacionais sofreram, evidentemente, muitas transformações: as relações humanas foram ressaltadas a partir da década de 1930, as abordagens sistêmicas emergiram, a teoria da contingência assumiu lugar de destaque, passando pelo determinismo ambiental de mercado até que, mais recentemente, as perspectivas teóricas do aprendizado organizacional, 
baseadas no conhecimento, permeassem o debate contemporâneo, profundamente marcado pela fragmentação teórica, bem como pelo pluralismo metodológico no campo das teorias organizacionais. De modo mais abrangente, a orientação dos modelos de análise de base científica durante a modernidade operaram por oposição binária, por exemplo, objetivismo e subjetivismo, estruturalismo e teoria compreensiva, taylorismo/fordismo e escola das relações humanas, etc. Por base na tentativa de exclusividades discursivas, as grand narratives constituem-se em obstáculos ao desenvolvimento das teorias científicas. Ou seja, esta constatação marca as primeiras características do que se denomina crise de paradigma da ciência moderna. Ao analisarmos as formas como as empresas buscam alguma sintonia com a sociedade, e desta sofrem influências, é no desenvolvimento dessas práticas que mais bem poderemos vislumbrar os ajustes e a interação entre o econômico e o social dentro e fora da organização. E tudo isto ao mesmo tempo. Compreender o comportamento das empresas, influenciado por outros agentes sociais, passa necessariamente pela abordagem das políticas e práticas de recursos humanos criticando, nessa abordagem, as correntes funcionalistas. Imaginar organizações a partir de uma racionalidade instrumental, no entanto, ainda permanece como algo hegemônico no pensamento administrativo.

A crescente importância dada ao fenômeno organizacional como algo socialmente construído pelos atores envolvidos no ambiente das organizações, faz com que as análises concentrem-se nos grupos, nas equipes, nas relações sociais estabelecidas, no comportamento gerencial etc. (CHANLAT, 2000; SAINSAULIEU e KIRSCHNER, 2006). Mas as explicações que envolvem o aprendizado não podem ser simplificadas ou reduzidas. 0 aprendizado individual, por exemplo, é um processo dinâmico (MINTZZBERG, AHLSTRAND, LAMPEL, 2000). Teorias como o behaviorismo, centrada na indução do comportamento, estimulada por variáveis externas, ou o modelo cognitivo, que busca analisar o aprendizado como percepção do indivíduo face a um processo de apreensão da realidade, fazem com que as abordagens referentes às organizações e aprendizagem se tornem um tema delicado e pouco consensual, do ponto de vista metodológico.

A partir da década de 1980, tendo em vista a mundialização da economia, surge a necessidade das organizações se adaptarem a novos contextos, de conhecerem suas relações eco-organizadas. A aprendizagem organizacional emerge nesse contexto histórico. Competitividade, diferenciação no mercado etc. pareciam sinalizar, uma vez mais, a necessidade de reconhecimento, por parte da organização, dos processos de mudança em contextos de risco, perigos, incertezas esurpresas.

No entanto, as organizações lidam com situações conflitantes ou paradoxais. Ao mesmo tempo em que, num ambiente de risco e grande competitividade, buscam reduzir incertezas, a aprendizagem faz com que a diversidade aumente, pois situações novas trazem inevitavelmente algum risco.

O sistema de recursos humanos de uma organização apresenta-se, portanto, como o foco intelectual da sistematização das organizações em seus processos de geração de auto identidade grupal e como imagem organizacional. RH corresponde, para além dos processos de auto-organização, aos processos de ajustes com o externo, aos processos de compreender e atuar sobre e sob condições ecoorganizadas. Em síntese, um subsistema facilitador da construção interna da organização frente às condições de eco-organização. Como resultado, uma conjunção moderadora em contextos de auto-ecoorganização.

É neste contexto de significativas mudanças e indefinições que surge esse novo tema. A expressão universidade corporativa surgiu "a partir da segunda metade da década de 1980, ante ao acirramento da competitividade em meio ao processo de internacionalização e globalização da economia" (MARCONDES, 2004, p. 271). Primeiro, no mundo empresarial, para depois ganhar espaço no mundo acadêmico. Sua conceituação não está legitimada na literaturai, mas sim na prática empresarial. 0 modelo das universidades corporativas foi desenvolvido para minimizar problemas advindos das práticas organizacionais (EBOLI, 2004).

Grande parte da literatura emprega as expressões "educação corporativa" e "universidade corporativa" como equivalente para tratar da educação que ocorre no âmbito formal das organizações. 
Observa-se também na literatura que os conceitos estão em evolução, o que representa um tema ainda em construção.

Como não há um consenso em torno do conceito de universidade corporativa, serão apresentados os principais entendimentos sobre o tema, na escassa literatura encontrada. As abordagens prescritivas, a partir de uma racionalidade gestionária, são as mais evidenciadas.

O conceito foi proposto em 1999 pela norte-americana Jeanne Meister (2005, p.29), descrevendo universidade corporativa como "guarda-chuva estratégico para o desenvolvimento e educação de funcionários, clientes e fornecedores, buscando otimizar as estratégias organizacionais".

Eboli (2004) define a concepção de universidade corporativa como um processo no qual os funcionários se envolvem em um constante aprendizado que visa melhorar o desempenho e aumentar sua produção nos negócios.

Para que uma ação educativa seja qualificada como universidade corporativa é necessário ter requisitos mínimos, que vão além do treinamento, pois precisa ao menos ter um programa de desenvolvimento e as atividades educacionais devem ter uma ligação clara com a estratégia corporativa (ALLEN, 2002).

A aprendizagem nas universidades corporativas passa a ser contínua, com programas sob medida, currículo flexível e alinhamento estratégico, realizados em parcerias com instituições educacionais, atendendo a empregados, clientes, fornecedores e comunidade (MEISTER, 2005; VERGARA e RAMOS, 2002).

A conexão entre universidades e aprendizagem organizacional é inevitável, pois ambas as concepções gestão podem ser compreendidas como processos de mudanças de comportamentos a partir das interações sociais nas organizações e dessas com relação aos sistemas externos. Concepção esta que se contrapõe aos modelos behavioristas, pois a cognicidade dos atores organizacionais formam a base do aprendizado grupal e organizacional, bem como as condições de relacionamento com o mercado. 0 que pode ser considerado um avanço significativo. Como perceber as diversas situações do cotidiano organizacional e analisá-las em um coletivo mais amplo proporcionariam, em princípio, a mudança organizacional. Viver essas experiências coletivas, refletir coletivamente sobre o significado das mesmas e internalizar valores comuns a partir de consensos grupais refletem e valorizam o papel do agente nas transformações organizacionais (VASCONCELOS e MASCARENHAS, 2007).

Giddens (2003) ressalta que todos os seres humanos são agentes cognoscitivos e que os agentes sociais possuem conhecimento e perfeita consciência de suas ações em suas vidas cotidianas.

Este argumento reflete a base argumentativa aqui defendida: há regularidades internas à organização em termos de membros e de cultura organizacional, mas que precisam ser observadas no conjunto dos fenômenos externos a esta mesma organização: portanto, a organização consiste em um sistema aberto e fechado, ou seja, auto-organizado (para si) e eco-organizado (para fora), em caráter dialógico ${ }^{\mathrm{ii}}$.

\section{OS MODELOS DE UNIVERSIDADE CORPORATIVA DESENVOLVIDO POR K. BARLEY}

Para Barley (2002), a estrutura de uma universidade corporativa pode ser afetada pela cultura organizacional, as hierarquias estabelecidas e os estilos de liderança. As melhores estruturas de universidades corporativas são aquelas que se harmonizam com as iniciativas e influências internas da organização, espelhando a cultura organizacional.

No entanto, os gestores devem compreender a cultura como algo que não pode ser gerenciado de forma planejada (BARBOSA, 2002; SROUR, 2005, SAINSAULIEU e KIRSCHNER, 2006). 0 papel dos administradores seria considerar a cultura um referencial para se compreender diferentes perspectivas, realizar diagnósticos, que podem e devem contribuir para as ações gerenciais, mas sem 
partir do pressuposto de que essa mesma cultura tenha um valor instrumental. 0 papel dos administradores deveria, portanto, considerar a cultura um referencial para se compreender o fenômeno organizacional a partir de diferentes perspectivas, respeitando as especificidades organizacionais e igualmente não considerar as organizações como esferas autônomas e dissociadas de um contexto social, político, histórico eambiental.

Ressaltando que as universidades corporativas são estratégicas na medida em que são planejadas e modeladas para cumprir a missão da organização, Barley (2002) explora diversos tipos de estruturas de universidades corporativas. Para que se obtenham indícios de um desenho organizacional que contemple uma universidade corporativa. É preciso considerar dois grandes eixos dessas estruturas que são o alinhamento corporativo e a organização do conteúdo, ou seja, o desenvolvimento de uma estrutura ou a imagem visual de como o conteúdo e o funcionamento de uma universidade corporativa deve ser organizado.

Quanto ao alinhamento corporativo, segundo Barley (2002), a posição da universidade corporativa dentro da estrutura da organização é um dos primeiros fatores a ser considerado quando se seleciona a forma ou o modelo de qualquer universidade corporativa. Existem três pontos citados pela autora, em que uma universidade corporativa pode alojar-se: diretoria executiva (abordagem top-down); departamento de recursos humanos (abordagem lateral); unidade de negócios (abordagem do esforço de base).

Barley (2002) afirma também que o desenvolvimento de uma estrutura ou a imagem visual de como o conteúdo e o funcionamento de uma universidade corporativa deve ser organizado é tão crítico para a aceitação da universidade pela organização quanto à posição em que ela se originou, foi lançada e será administrada. A maneira como o conteúdo é organizado deve ajustar-se à estrutura e à cultura da organização. A autora apresenta cinco modelos de organização doconteúdo.

Este modelo permite identificar facilmente trilhasiii de aprendizagem que podem percorrer, por estarem diretamente vinculadas às unidades em que operam. 0 modelo do templo de Barley, por sua vez, tem forte conexão acadêmica, pois é usado para retratar a educação superior e a estabilidade da aprendizagem tradicional. Assim como o modelo do organograma, ele retrata a hierarquia ou a seqüência dos passos da aprendizagem. A aprendizagem básica é a base para o desenvolvimento multifuncional que, por sua vez, leva à aprendizagem específica e, por último, culmina com a aprendizagem executiva ou de desenvolvimento de liderança. 0 modelo da pirâmide de Barley, como no modelo do templo, inclui a idéia da hierarquia, ou seja, os programas básicos levam às áreas mais especializadas.

Conceitualmente, o modelo mostra a aprendizagem como sendo mais ampla na base e mais específica à medida que a figura vai se estreitando, finalizando com os programas executivos ou de liderança, no ápice. Por sua vez, o modelo da torta corporativa, do mesmo autor, é uma maneira fluida de agrupar e formatar as oportunidades de aprendizagem dos empregados. A aprendizagem básica posiciona-se no centro, visualizando claramente a sua importância. Permite a integração rápida de novas unidades de conteúdos específicos e de novos anéis, se necessário, tornando-o adaptável a uma organização que esteja em processo de expansão interna ou de fusão com outras empresas. Novas unidades de conteúdos podem ser incluídas sem prejudicar as existentes e sem violar a integridade do modelo. 0 modelo de torta corporativa considera o desenvolvimento de liderança como sendo equivalente às outras unidades de conteúdo. Há ainda o modelo do catavento e, de todos os modelos de conteúdo descritos pela autora, o do catavento é talvez o mais consistente e o que melhor retrata a proposta integral de uma verdadeira universidade corporativa. Como no modelo da torta corporativa, a aprendizagem básica do modelo catavento fica no centro do círculo e é circundado por anéis de aprendizagens multifuncionais e específicas. 0 que o distingue do modelo da torta corporativa, porém, são as setas que projetam a aprendizagem para fora do anel interno, saindo da abordagem centrada unicamente no empregado enfatizando o componente externo, uma vez que os programas de aprendizagem não são feitos somente para o uso interno dos empregados, mas também externamente para uma variedade de afiliados à organização, com base na concepção de que todos contribuem para 
o crescimento e a efetividade da organização.

Não importa se a organização é profissional, acadêmica, hierárquica, circular ou progressiva, pois a estrutura de uma universidade corporativa, a imagem gráfica dela e o arranjo do conteúdo devem se adaptar às diferenças e as mudanças encontradas e orientar a maneira como os empregados compreendem a conexão existente entre currículo e desempenho funcional. Algumas organizações aproveitam as boas práticas de outras organizações, mas enquanto um modelo funciona bem para uma empresa, para outra já pode encontrar resistência na adoção do mesmo modelo (BARLEY,2002).

Para Barley (2002), no alinhamento corporativo reside a base para a institucionalização de uma universidade corporativa. Ao escolher um modelo de universidade corporativa, o desenho organizacional e o posicionamento da "universidade" no contexto organizacional são determinante para o reconhecimento, aceitação e fortalecimento da mesma rente ao quadro de pessoas que desenvolvem atividades profissionais na organização. Outro eixo explorado pela autora é relativo à organização do conteúdo dentro da universidade corporativa. Segundo a autora, desenvolver uma estrutura ou um diagrama de como o conteúdo e o funcionamento deve ser organizado é tão crucial para o sucesso de uma universidade corporativa como a posição onde ela se originou e está sendo administrada.

\section{CONSIDERAÇÕES FINAIS}

A universidade corporativa pode se apresentar de diferentes formas quanto ao posicionamento que ocupa dentro da estrutura organizacional ou quanto à organização do conteúdo. Mas a forma como a organização escolhe e define estes modelos deve ser flexível o suficiente para combinar com a cultura organizacional e garantir que estejam alinhadas com suas estratégias organizacionais, com a missão, a visão e os valores (BARLEY, 2002).

Os estudos envolvendo organizações devem partir da compreensão e análise das áreas de recursos humanos, ou da estrutura das mesmas, para que análises comparativas sobre as semelhanças possíveis entre a concepção de aprendizagem nessas organizações e os desenhos, ainda que embrionários, de universidades corporativas. Mas é preciso um rigor para que limites sejam observados para que as diferenças sejam ressaltadas. 0 marketing envolvendo novas iniciativas no campo da gestão tem sido uma constante na divulgação das inovações corporativas. Uma área de TeD 'pretensiosa' não pode ser confundida com o conceito abrangente de universidade corporativa.

Esses novos modelos de gerenciamento, baseado em valores, não estão isentos de ambigüidade, pois apesar dos discursos valorizando a participação das pessoas no ambiente organizacional, a alta administração estará sempre na expectativa de lucratividade crescente. Lipovetsky (2005, p. 248), numa perspectiva mais crítica, ressalta que a intenção dos gestores, em última instância, é algo "[...] inconfessável, e não pode ser invocado sem que se anule o processo participativo, o qual pressupõe um objetivo superior a si mesmo". O próprio conceito de aprendizagem organizacional apresenta-se distante de qualquer tipo de consenso (WEICK e WESTLEY, 2004).

Seria, portanto, precipitado ressaltar avanços de organizações na configuração de universidades corporativas? Acredita-se que sim, embora o campo necessite de pesquisas empíricas que comprovem, ou não, hipóteses que reforçam a concepção que novos modelos de universidades corporativas adquirem aceitação no Brasil e que há, de fato, processos envolvendo a institucionalização desses modelos em empresas brasileiras.

Importante também é não esquecer as ambigüidades inerentes novos discursos envolvendo os modelos de gestão de pessoas, universidades corporativas, dentre outros com um 'colorido' humanista e a, por outro lado, a partir da lógica do capital, a busca efetiva por resultados, inerente a qualquer organização privada. Mais do que nunca, é preciso cautela ao analisarmos novos conceitos e práticas de gestão. 


\section{REFERÊNCIAS}

ALLEN, M. Introduction: what is a corporate university, and why should an organization have one? In: ALLEN, M. (Org.). Corporate University Handbook: designing, managing, and growing a sucessful program. New York: Amacon, 2002.

ASTLEY, G., W.; VAN DE VEM, Andrew H. Debates e perspectivas centrais na teoria das organizações. In: CALDAS, Miguel P.; BERTERO, Carlos O. (Coords.). Teoria das organiações. São Paulo: Atlas, 2007. p. 80-116.

BARBOSA, L. Cultura e empresas. Rio de Janeiro: Jorge Zahar Ed., 2002.

BARLEY, K. Corporate University Structures. That reflect organizational Cultures. In: ALLEN, M. (Org.). Corporate University Handbook: designing, managing, and growing a sucessful program. New York: Amacon, 2002.

BAUMAN, Z. Modernidade líquida. Rio de Janeiro: Jorge Zahar, 2001.

BERTERO, C.O. Ensino e pesquisa em Administração. São Paulo: Thomson Learning, 2006.

BOLTANSKI, L. CHIAPELLO, E. O novo espírito do capitalismo. São Paulo: WMF Martins Fontes, 2009.

CASANOVA, P. G. As novas ciências e as humanidades: da academia à política. São Paulo: Boitempo, 2006.

CHANLAT, J.F. Ciências Sociais e management. Reconciliando o econômico e o social. São Paulo: Atlas, 2000.

CLEGG, S. R.; HARDY, C.Organização e estudos organizacionais. In: CLEGG, S. R.; HARDY, C.; NORD, W. R. (Orgs.). Handbook de estudos organizacionais. Modelos de análises e novas questões em estudos organizacionais. São Paulo: Atlas, 1998, v.1. p. 27-57.

DAVEL, E.; VERGARA, S. C. Gestão com pessoas, subjetividade e objetividade. In: DAVEL, E.; VERGARA, S. C. Gestão com pessoas e subjetividade. São Paulo: Atlas, 2010. p. 3-27.

EBOLI, M. Educação corporativa no Brasil: mitos e verdades. São Paulo: Editora Gente,2004.

FREITAS, M.E. Cultura organizacional. Evolução e crítica. São Paulo: Thomson Learning, 2007.

GARCÍA, R. Interdisciplinariedad y sistemas complejos. IN: LEFF, Enrique (Org.). Ciências sociales y formación ambiental. Barcelona: Gedisa, 1984. p. 85-124.

GAULEJAC, Vincent de. Gestão como doença social. Ideologia, poder gerencialista e fragmentação social. Aparecida, SP: Idéias e Letras, 2007.

GARRIDO, P.O. Educação corporativa policêntrica: aplicação trans-disciplinar da engenharia pedagógica para a produção da aprendizagem transformadora. Tese do Programa de pósgraduação em engenharia de produção. Florianópolis: UFSC, 2006.

GIDDENS, Anthony. A constituição da sociedade. São Paulo: Martins Fontes, 2003.

HOGAN, D. J.; VIEIRA, Paulo F. (Orgs.) Dilemas socioambientais e desenvolvimento sustentável. Ed. UNICAMP, 1992.

MARCONDES, R.C. Desenvolvendo Pessoas: do Treinamento e Desenvolvimento à Universidade Corporativa. In: Construindo a gestão do fator humano. Cap. 9. São Paulo: Editora Saraiva, 2004. 
MORIN, E. 0 método 3: o conhecimento do conhecimento. 2 ed. Porto Alegre: Sulina, 1999.

Ciência com consciência. 5 ed. Rio de Janeiro: Bertrand Brasil, 2001.

Complexidade e ética da solidariedade. In: CASTRO, Gustavo de (Coord.). Ensaios de complexidade. 3 ed. Porto Alegre: Sulina, 2002a. p. 11-20.

. Introdução ao pensamento complexo. Porto Alegre: Sulina, 2005.

0 método 3: o conhecimento do conhecimento. 2 ed. Porto Alegre: Sulina, 1999.

O problema epistemológico da complexidade. Mem-Martins, Portugal: Publicações EuropaAmérica, 2002.

MASCARENHAS, A. O.; VASCONCELOS, F. C.; VASCONCELOS, I. F. G. Gestão do paradoxo: discurso versus prática - aprendizagem e informatização da administração de RH. In: VASCONCELOS, F.; VASCONCELOS, I. F. G.. Paradoxos organizacionais: uma visão transformacional. São Paulo: Pioneira Thomson, 2004. p. 75-106.

MEISTER, J.C. Educação corporativa: a gestão do capital intelectual através das universidades corporativa. São Paulo: Makron Books, 2005.

MEISTER, J. C. Corporate Universities; lessons in building a world-class work force. Rev. and updated edition. New York: McGraw Hill, 1998.

MARCARENHAS, A.O.; KUNDA, G.; VASCONCELOS, I.F.G. Cultura organizacional e antropologia interpretativa - ultrapassando a abordagem de integração na pesquisa e na prática. In: VASCONCELOS, F. C.; VASCONCELOS, I.F. G. Paradoxos organizacionais: uma visão transformacional. São Paulo: Pioneira Thomson, 2004. p. 197-229.

MINTZBERG, H.; AHLSTRAND, B.; LAMPEL, J. Safári de estratégia. Um roteiro pela selva do planejamento estratégico. Porto Alegre: Bookman, 2000.

NOGUEIRA, M. A. Um Estado para a sociedade civil. São Paulo: Cortez, 2004. p.309-335.

LACOMBE, B. M. B.; TONELLI, M. J. O paradoxo básico da administração de recursos humanos: o discurso versus a prática de gestão de pessoas na empresa. In: VASCONCELOS, F. C. e VASCONCELOS, I.F.G. Paradoxos organizacionais: uma visão transformacional. São Paulo: Pioneira Thomson Learning, 2004. p. 53-74.

LIPOVETSKY, G. A sociedade pós-moralista. O crepúsculo do dever e a ética indolor dos novos tempos democráticos.Barueri, SP: Manole, 2005.

PAES DE PAUlA, A. P.; WOOD Jr., T. Pop-Management. In: WOOD Jr., Thomaz (Org.). Mudança organizacional. São Paulo: Atlas, 2004. p. 83-138.

REED, M.. Teorização organizacional: um campo historicamente contestado. In: CLEGG, S. R.; HARDY, C.; NORD, W. R. Handbook de estudos organizacionais: modelos de análise e novas questões em estudos organizacionais. São Paulo: Atlas, 1998. p.61-98.

SANTOS, B. S. Introdução a uma ciência pós-moderna. 4 ed. Rio de Janeiro: Graal,1989.

Para um novo senso comum: a ciência, o direito e a política na transição paradigmática. São Paulo: Cortez, 2000.

SAINSAULIEU, R.; KIRSCHNER, A. M. Sociologia da empresa: organização, poder, cultura e desenvolvimento no Brasil. Rio de Janeiro: DPA Editora, 2006. 
SROUR, R. S. Poder, cultura e ética nas organizações. O desafio das formas de gestão. Rio de Janeiro: Elsevier, 2005.

TEIXEIRA, A. Universidades Corporativas X Educação Corporativa. O Desenvolvimento do Aprendizado Contínuo. Rio de Janeiro: Qualitymark, 2001.

VASCONCELOS, I.F.G.; MASCARENHAS, A.O. Organizações em aprendizagem. São Paulo: Thomson Learning, 2007.

VERGARA, S.C.; RAMOS, D.R.M. Motivos para a criação de universidades corporativas - Estudo de casos. Revista de Administração Mackenzie, Ano 3, n.2, p. 79-98, 2002.

VIEIRA, P. F. Gestão patrimonial de recursos naturais: construindo o ecodesenvolvimento em regiões litorâneas. In: CAVALCANTI, C. (Org.). Desenvolvimento e natureza: um estudo para sociedade sustentável. 2 ed. São Paulo: Cortez; Recife, PE: Fundação Joaquim Nabuco, 1998. p.293-322.

WEICK, K.; WESTLEY, F. Aprendizagem organizacional: confirmando um oxímoro. In: CLEGG, Stewart; HARDY, Cyntia; NORD, Walter. Handbook de estudos organizacionais: ação e análise organizacionais. v.3. São Paulo: Atlas, 2004. p. 361-388.

WOOD Jr., T. Mudança organizacional e transformação da função de recursos humanos. In: WOOD JR. (Org.). Mudança organizacional. São Paulo: Atlas, 2004. p.268-289.

\section{NOTAS}

\footnotetext{
${ }^{\text {i }}$ Profissionais e acadêmicos tem se apoiado na publicação de J.C. Meister desde o ano de 1999 e M. Eboli partir de 2001 para discutir os processos de implantação e de gestão das universidades corporativas. São poucas as obras editadas no Brasil que contemplam o tema "universidades corporativas".

ii Pelo princípio dialógico é "impossível chegar-se a uma unificação primeira ou última, a um princípio único, a uma solução monista. Aplicar esse princípio significa articular, mantendo a dualidade no seio da unidade, sem pretender realizar uma síntese, como acontece na dialética. Simplificando o pensamento dialético (...) tendo-se uma tese (...) e uma antítese (...) teriase como síntese (algo que) teoricamente contém (tese e antítese). Entretanto, essa síntese dialética não (preservaria a tese e a antítese, pois) desaparecem na (síntese) (...). A dialógica ("e - e") é capaz de unir conceitos que tradicionalmente se opõem, considerados racionalmente antagônicos, e que até então encontravam-se em compartimentos fechados (VASCONCELLOS, 2003, p. 113-114). De outro modo, no princípio dialógico recursivo "o que é produzido e gerado torna-se o produtor e gerador daquilo que produziu ou gerou. Cultura e Sociedade estão em interdependência generativa e, nessa interdependência, não devemos esquecer as interações entre os indivíduos, que são, eles mesmos, portadores/transmissores de cultura; essas interações regeneram a sociedade que, por sua vez, regenera a cultura (...) 0 conhecimento está, portanto, em todos os sentidos ligado à estrutura da cultura, à organização social, à realidade histórica. Neste contexto ele não é somente condicionado, determinado e gerado, mas ele próprio também atua como coordenador, determinante e gerador (MORIN, 1995, p. 72 e 80).

iii Utilizamos, em tradução livre, as expressões track (no original trilhas) para definir a noção de direção e da seqüência dos passos da aprendizagem.
} 